\title{
LA SEGURIDIZACIÓN DE LA CONFERENCIA REGIONAL SOBRE MIGRACIÓN
}

\section{THE SECURITIZATION OF THE REGIONAL CONFERENCE ON MIGRATION}

\section{María Eugenia Solís Vargas*}

\begin{abstract}
RESUMEN
En este artículo, se analiza cómo la priorización de enfoques sobre la seguridad, junto con los cambios en el complejo de seguridad, han influenciado el discurso de la Conferencia Regional sobre Migración en la I y la XIX conferencias. A partir del análisis de contenido, se indican las diferencias discursivas en la Conferencia Regional de Migraciones, entre 1996 y 2014. Se evidencia que la conferencia ha experimentado un proceso de cambio en el cual se
\end{abstract} pasa de un enfoque de derechos humanos a uno de seguridad.

PALABRAS CLAVE: POLÍTICA INTERNACIONAL * SEGURIDAD INTERNACIONAL * MIGRACIONES * ORGANIZACIÓN REGIONAL * COOPERACIÓN REGIONAL

\section{ABSTRACT}

This article analyzes how the prioritization of safety approaches together with changes in the security complex, have influenced the discourse of the Regional Conference on Migration in the I and XIX conference. Using content analysis to mark the discursive differences in the Regional Conference on Migration, between 1996 and 2014. Demonstrating that the conference has gone through a process of change, passing from a human rights approach to one of security.

KEYWORDS: INTERNATIONAL POLITICS * INTERNATIONAL SECURITY * MIGRATION * REGIONAL ORGANIZATIONS * REGIONAL COOPERATION 


\section{INTRODUCCIÓN}

La dinámica de las migraciones es compleja y cambiante, la pluralidad de actores es una de sus características más importantes. Las organizaciones internacionales, tanto gubernamentales como no gubernamentales, son parte de estos actores cuya relevancia se destaca por la globalización intrínseca de los movimientos migratorios. Entre ellas, se destaca la Organización Internacional para las Migraciones (огм), si bien este organismo internacional no es originariamente parte de la Organización de la Naciones Unidas (onu), en setiembre de 2016 se firma un acuerdo mediante el cual se incorpora a la oIm dentro del sistema de onu (Centro de Noticias onu, 2016). Este organismo ejerce influencia "por medio de la producción de conocimiento, la asesoría "científica" o "técnica" a los estados y el desarrollo de programas, ya sea por encargo de los gobiernos o en forma directa, mediante la puesta en práctica de políticas" (Kron, 2011, p.59).

Gran parte del trabajo de la огм se ha centrado en los Procesos Regionales Consultivos sobre Migración (PRc), foros restringidos de intercambio de información y deliberación para países organizados regionalmente en diversas partes del mundo para promover la cooperación en el ámbito de la migración con la finalidad de incentivar la gobernanza internacional de esta (огм, 2013). Entre estos, se encuentra la Conferencia Regional sobre Migración (сRм) que abarca América del Norte y América Central. La cRm está bajo la dirección de la oIm, la cual administra los fondos, coordina las actividades y prepara talleres para la capacitación de los funcionarios desde su oficina regional, con sede en San José, Costa Rica.

Este es un foro intergubernamental que se centra en la dinámica migratoria de la región. Un elemento importante de este foro en particular es que abarca los países que son de destino (Canadá, Ee.uu., Republica Dominicana), así como de tránsito y de origen de migrantes (México, Guatemala, Honduras, El Salvador, Belice, Nicaragua, Costa Rica y Panamá). En el régimen, también convergen Estados observadores, como Argentina, Colombia y Perú, entre otros; así como, la Red Regional de Organizaciones
Civiles para las Migraciones (RROcM), también con estatus de observador. Si bien, la cRм no tiene carácter vinculante, es un espacio de diálogo trascendental que responde a importantes necesidades de la región.

La cRm debe ser entendida como un regionalismo en tanto es "un programa de carácter regional guiado por los Estados con base en negociaciones $y$ tratados intergubernamentales" (Börze, Goltermann, Lohaus y Striebinger, 2012, p.4, traducción propia). Además, es importante considerar cómo plantea Farrell (2005), que esta emerge de las dinámicas propias de la región, incluidas la importancia del fenómeno migratorio, así como, las estrategias $y$ motivaciones de los actores regionales. En este caso, EE.uu. es el principal actor regional y por ser el principal receptor de migrantes de la región posee un especial interés en establecer controles y coordinación, asimismo otros actores se benefician de diversos modos al aplicar estas políticas.

En los últimos años, se ha podido identificar en el tema migratorio un fenómeno de "seguridización", en el que asuntos que antes no eran considerados, ni abarcados con un enfoque de seguridad, pasan a ser tratados de esta manera. En el caso de las migraciones, esto implica una problemática al criminalizarlas. Se consideran estos tres factores: interdependencia, seguridización y la cRM. Se analiza cómo estos se interrelacionan y culminan en la priorización de la seguridad en una organización cuyo origen estaba centrado en los derechos humanos (DD.нH.).

Para lograr esto, se desarrolla una conceptualización que abarca los temas de seguridización y una breve introducción a la teoría de los complejos de seguridad expuestos por Barry Buzan (Buzan, 1991; Buzan et ál., 1998). Ambos aspectos teóricos son aplicados a la realidad regional y orientados a la temática de las migraciones. Seguidamente, se incluye un análisis de las declaraciones que se desprenden de la s y xix Conferencia Regional sobre Migración.

\footnotetext{
1 "Seguridización" es un término acuñado por Barry Buzan, Ole Wæver y Jaap de Wilde (1998), en la obra Security: A new framework for analysis. También es traducido como "securitización".
} 
La metodología utilizada en este caso fue el análisis de contenido. Los documentos analizados o unidades de observación son el Comunicado Conjunto de la I Conferencia Regional sobre Migración realizada en Puebla, México, en marzo de 1996. En este, se muestran los orígenes de la conferencia por ser el documento fundacional. El documento fue contrastado con los textos que surgen de la xix Conferencia Regional sobre Migración realizada en el 2014, la última al inicio de la preparación de este artículo. Para esta última, se analizan tanto la Declaración como las Decisiones de Viceministros y Viceministras en la xix CRM, y la Declaración Extraordinaria, realizadas en Managua, Nicaragua en junio de 2014. Estos escritos fueron seleccionados con la finalidad de mostrar las diferencias existentes entre el enfoque que tenía la CRM en su creación y el enfoque que presenta actualmente, comparando el vocabulario y el discurso empleados.

Primero se busca responder mediante un análisis de los documentos las cuatro preguntas básicas, según Abarca (2013): ¿qué se quiere decir?, ¿quién o quiénes son los destinatarios de lo que se dice?, ¿para qué se dice?, ¿cuál es la intensidad con la que se dice?, segundo, se efectúa un análisis del cambio de discurso. Con esto, se pretende mostrar cómo los cambios dados en el complejo de seguridad han afectado el discurso sobre el fenómeno migratorio y cómo esto ha influido en la seguridización en la cRM; tercero, se realiza un conteo de palabras clave, las cuales son clasificadas en dos categorías, palabras relativas a los DD.нн. $y$ aquellas relativas a la seguridad.

Es importante reconocer que el conteo de palabras y la subsecuente clasificación de estas, no es la única manera de analizar el discurso, ni es absoluta en sus conclusiones. Se utiliza como un indicador y se refuerza con una lectura a profundidad $y$ un análisis de los documentos. A partir de la respuesta a las preguntas planteadas, el conteo de palabras y el análisis de los documentos se pretende explicar el cambio discursivo surgido en la Conferencia Regional sobre Migración de acuerdo al contexto donde se desarrolla. Finalmente, se presentan las conclusiones generales del documento.

\section{LA SEGURIDAD, LA SEGURIDIZACIÓN Y EL COMPLEJO DE SEGURIDAD}

El concepto de seguridad, como muchos otros en las ciencias sociales, es ambiguo, y diferentes autores han optado por diversas definiciones. En el marco de este artículo, se debe partir de las siguientes consideraciones: 1) la concepción de seguridad cambia dependiendo de cuál sea el referente de esta, es decir, a quién se aplica; 2) la seguridad, en su sentido tradicional, es un concepto amplio el cual funciona como idea organizativa $y$ abarca temas como "la carrera de armamentos, la industria armamentística, el comercio y la inversión internacionales, la elaboración de política exterior, dinámica del sistema y la soberanía, los cuales pueden conectarse dentro de un marco amplio" (Orozco, 2005, p.163); 3) la seguridad humana parte de un referente distinto, como señala el Instituto Interamericano de Derechos Humanos (I.I.D.H.):

La reconceptualización del concepto de seguridad, el cual ya no se fundamenta en las nociones de soberanía, territorialidad y poderío militar que fueron tradicionales, sino en lograr la libertad del miedo y la libertad de la necesidad o de la miseria (I.I.D.H., s.f., p.1).

Al hablar de seguridad nacional se prioriza la integridad del Estado y se enfrentan amenazas externas o movimientos internos que lo sitúen en peligro. Al considerar la seguridad humana, el énfasis se ubica en el individuo y se contemplan factores como los DD.Hн. El concepto de seguridad no es estático, sino que evoluciona con la realidad internacional. Si bien, la seguridad puede ser definida como "una condición relativa de protección en la cual se es capaz de neutralizar amenazas identificables contra la existencia de alguien o de alguna cosa" (Cepik citado en Marcano y Maldonado, 2004, p.128), lo que cambia son las concepciones de amenazas.

Por ejemplo, un elemento que no era concebido anteriormente como una amenaza puede formar parte de los temas de seguridad 
si es seguridizado. Se plantea que un tema ha sido seguridizado cuando "el asunto es presentado como una amenaza existencial, que requiere medidas de emergencia $y$ justifica acciones fuera de los límites normales de procedimiento político" (Buzan et ál, 1998, p.23-24). Ello remite a la seguridización como la acción de presentar un tema como una amenaza y plantear medidas de emergencia y seguridad en torno a este. Han surgido cambios tanto en el contexto regional, desde la concepción de amenazas hasta eventos específicos, como en el discurso de la cRM.

Estas medidas de emergencia sobresalen particularmente cuando hay detención de migrantes, pues "existen campos en los se confina a personas migrantes que no han cometido ningún delito. El tiempo de estancia y las garantías jurídicas difieren según el país, pero la esencia del estado de excepción está presente" (González, 2012, p.12). Este trato injustificado y el estado de excepción mencionado por González son evidencia de la seguridización de las migraciones, ya que se aplican tratos propios de tiempos de guerra y asociados con los elementos propios de la seguridad nacional a las personas migrantes, $y$ se dejan de lado los DD.HH. $y$ los objetivos propios de la seguridad humana.

Buzan (1991) define un complejo de seguridad como "un grupo de Estados cuyas principales preocupaciones se enlazan lo suficiente para que sus seguridades nacionales no puedan ser realmente separadas unas de otras" (p.106, traducción propia). Situación que afecta las interacciones entre los países $y$ en ocasiones genera incluso la aparición de instituciones formales. Con base en la definición anterior, y por su cercanía e interconexión geográfica y económica, se puede percibir que existe un complejo de seguridad que va desde Panamá hasta Canadá; el cual incluye países con muy distintas realidades, pero que confluyen cuando analizan las amenazas a las que se enfrentan en materia de seguridad. Buzan (1991) evidencia en el concepto de complejos de seguridad una interdependencia entre los Estados como una característica importante de la realidad internacional, al señalar que las seguridades nacionales no pueden separarse.
Los efectos de esta interdependencia se filtran a las interacciones de los países y de los foros internacionales. Precisamente esto es lo que se debe analizar en el caso de la сRм y sus once países miembros, cuya seguridad se encuentra entrelazada. Esta situación evidencia lo importante que es un acercamiento conjunto a la seguridad, la cual tradicionalmente se ha entendido como un tema que debe manejarse de manera individual. Asimismo, debe analizarse el papel que desempeña la región, particularmente al considerar cómo se afectan los Estados en temas de narcotráfico, migraciones, trata de personas $y$ en el accionar del crimen organizado, en general. Se puede señalar que todas estas amenazas afectan de uno u otro modo la seguridad en alguno de sus referentes. En el caso de la сRм, la visión de la trata de personas como una amenaza común fue lo que motivó el trabajo conjunto:

El discurso contra la trata de personas puede ser considerado como la narrativa fundacional del Proceso Puebla, en tanto que presenta la migración irregular como una amenaza común extrarregional para todos los países norte y centroamericanos. Así, dicho discurso creó un consenso y legitimó una mayor cooperación multilateral, al colocar a los países del Istmo en una posición de supuestos socios en pie de igualdad (Kron, 2011, p.65).

Desde una división subregional tradicional, es posible argumentar la existencia de dos complejos de seguridad diferenciados: uno centroamericano $y$ otro norteamericano; sin embargo, esto podría generar confusión en el momento de analizar a América Central, ya que se ve altamente afectada por las decisiones de los países del norte, particularmente Ee.uu., en tanto es un referente en seguridad, $y$, una importante fuente de cooperación en la lucha contra el crimen organizado. No obstante, también esta región se ve afectada por Centroamérica la cual funciona como un puente entre los países sudamericanos y norteamericanos. De acuerdo con esta consideración, no parece ser necesaria 
una diferenciación, aunque es evidente que no todas sus preocupaciones se ven conectadas.

En este complejo de seguridad, se pueden percibir tres características, tal como lo plantean Benítez y Sotomayor (2008). Primeramente, en la mayor parte del complejo, predomina el dilema de inseguridad, ya que la principal vulnerabilidad es la ausencia de seguridad interna. Simultáneamente los problemas de seguridad convencionales son menos relevantes, como se puede observar por la ausencia de conflictos territoriales y el bajo gasto militar. Si bien EE.uU. se ve principalmente afectado por el dilema de la seguridad tradicional, también enfrenta amenazas no convencionales caracterizadas por el accionar del crimen organizado. En segundo lugar, la seguridad en la región es un tema interméstico, es decir, el problema conlleva causas de carácter nacional, pero sus efectos son transnacionales. Esto se da porque los problemas de América Central y México afectan directamente a Ee.uu. y Canadá.

Por último, el complejo se caracteriza por la ausencia de una comunidad de seguridad "en una comunidad así definida la función de las Fuerzas Armadas ya no es la de intimidar o disuadir, sino la de proteger a los Estados frente a una agresión externa" (Benítez y Sotomayor 2008, p.388). Todavía se está lejos de eso, ya que en algunos de los Estados la supremacía del poder civil no se ha logrado establecer completamente, pues los incentivos para aumentar la cooperación en las áreas de concertación y confianza son inexistentes, asimismo, hay diferencias ideológicas que datan desde la época de la Guerra Fría. Un buen ejemplo de esto se puede identificar en la reciente compra de armamento por parte de Nicaragua, la cual generó desconfianza en la región y fue percibida negativamente por los otros países centroamericanos; por ejemplo, la prensa hondureña indicó que analistas nacionales — como Carlos Flores $\mathrm{Pa}$ guada-, experto en defensa y seguridad, consideran esto una amenaza para Centroamérica (Panting, 2016).

El complejo de seguridad enfrenta una dicotomía marcada por las diferentes capacidades estatales y los disparejos acercamientos a las problemáticas. Frente a los esfuerzos de
EE.uu., se presenta una realidad muy diferente dada parcialmente por una institucionalidad débil y la ausencia de control que existen en Centroamérica y México. La región entera se ve afectada por la internacionalización del crimen organizado, el cual cada vez parece tener más poder y más medios. Esto genera la necesidad de mayores controles, los cuales son costosos de ejercer de manera unilateral. Además, se vuelven particularmente complicados especialmente en las fronteras de los países centroamericanos que son altamente frágiles y porosas.

La fragilidad de los Estados, tanto en el ámbito general como en el institucional, permite al crimen organizado operar fácilmente. Las organizaciones de crimen organizado encuentran un nicho en Centroamérica, ya que "sus fronteras son profundamente porosas, con poco control gubernamental $y$ en ellas predominan las mafias, redes del crimen organizado, tráfico de personas y corrupción institucional" (Benítez y Sotomayor, 2008, p.387). A partir de este nicho y por las características geográficas de la región, estas organizaciones delictivas tienen acceso a Ee.uu. y Canadá, constituyendo uno de los principales problemas de seguridad. Aunado a esa porosidad fronteriza de la que se aprovecha el crimen organizado, existe una compleja dinámica migratoria.

\subsection{LAS MIGRACIONES EN UN CONTEXTO DE SEGURIDAD}

La migración es el "movimiento de población hacia el territorio de otro Estado o dentro del mismo que abarca todo movimiento de personas sea cual fuere su tamaño, su composición o sus causas; incluye migración de refugiados, personas desplazadas, personas desarraigadas, migrantes económicos" (огм, 2006, p.38). En este documento y en el contexto de la CRM, al nombrar la migración se hace referencia a la migración internacional, determinada por el cruce de fronteras.

La realidad de las migraciones en la región ha sido analizada por parte de organismos como оाм, en donde un informe del 2012 titulado The state of migration management in Central America, reconoce que la exclusión social es uno de los factores más relevantes de 
la migración irregular, sin embargo "el informe termina criminalizando los pasos irregulares de las fronteras y a los residentes de los pueblos fronterizos y proponiendo únicamente soluciones técnicas o punitivas" (Kron, 2011, p.66). Esto debe ser ampliado pues elementos como la criminalidad de la región han afectado los flujos migratorios. Se presentan tanto migraciones económicas, marcadas por las dificultades socioeconómicas que se presentan en Centroamérica, como desplazamientos forzados o causados por el accionar del crimen organizado (сіDeнuм, 2012, p.6). Esto tiene como resultado una dinámica migratoria muy compleja en ambas regiones.

Otro aspecto relevante para la contextualización del fenómeno migratorio en la región es la crisis de la niñez migrante, así como, la feminización de las migraciones. El primero hace referencia a la situación en la que miles de menores centroamericanos no acompañados, particularmente del Triángulo del Norte, fueron encontrados en la frontera con Estados Unidos.

La crisis de la niñez migrante en EE.uu. se disparó con la aprehensión de 36260 menores no acompañados provenientes de México y Centroamérica (us Customs and Border Protection, s.f), en el año fiscal 2014. Estos datos históricos, llamaron la atención de las autoridades y de la prensa internacional. Estos hechos requieren una respuesta internacional, la cual se da tanto a lo interno en EE.uu, como en el ámbito internacional, mediante acuerdos de cooperación entre los Ee.uu. y los diferentes países de origen de los menores. Además, en el seno de la CRM se presenta una declaración extraordinaria cuyo contenido se analizará posteriormente.

Frente a esta dinámica migratoria, la respuesta ha sido la seguridización como un esfuerzo de control liderado por los países receptores. Conscientes de que la realidad internacional y regional es dinámica, se deben considerar esos factores y el marco que representa el complejo de seguridad. La interdependencia generalizada dada por los procesos de globalización, la facilitación del transporte y los constantes intercambios o flujos que hay en las fronteras hacen casi imposible el control fronterizo. Sin embargo, hay quienes insisten en ejercer ese control a tal punto que se involucran elementos de la seguridad nacional o militar. De esta manera, se ha generalizado que las migraciones se han convertido en un tema de la seguridad estatal:

La academia especializada en cuestiones de seguridad, así como la mayoría de los actores sociales implicados en temas migratorios, coinciden en que las migraciones internacionales, los movimientos de personas, en definitiva, la movilidad humana, se ha convertido en un punto esencial de la agenda de seguridad de los países desarrollados, tanto en el plano interno, como en el internacional (González, 2012, p.4).

Esto es un ejemplo de cómo la dinámica migratoria ha sido un elemento que se ha seguridizado. Este autor sostiene que la seguridización de las migraciones se manifiesta de dos formas. En primer lugar, mediante la definición de las migraciones como una amenaza, lo que genera que el tema se incorpore en las agendas de seguridad, tanto en el plano nacional como internacional (González, 2012). Más adelante se ahondará sobre la manera mediante la cual el tema se introduce en la agenda regional de la CRM a través de temas específicos como: la trata de personas y el tráfico de migrantes, los cuales han sido aplaudidos como éxitos del Proceso Puebla, identificables claramente en la adopción de legislación que contempla tanto el tráfico ilícito de migrantes $y$ la trata de personas como delitos penales, así como la protección de las víctimas.

En segundo lugar, se señala que a través de la subordinación de espacios en la cooperación internacional, se exigen requisitos como la colaboración en temas de seguridad. Esta situación que se puede ejemplificar con la Iniciativa Mérida, que en el ámbito de combate al narcotráfico incluye también un espacio de seguridad fronteriza que concierne a las migraciones, "facilitar el comercio legítimo y tránsito de personas mientras se restringe el flujo ilícito de drogas, personas, armas y efectivo" (us Embassy-México, 2015, p.2). 
Eventos como los ataques del 11 setiembre de 2001 redefinieron el análisis de la seguridad mundial $y$ también produjeron efectos directos en la región. A partir de este hecho, EE.uu. inició una cruzada para ejercer mayor control en el ingreso al país y disminuir la porosidad de sus fronteras, por las cuales transitan irregularmente mercancías, armas, drogas y personas. Massey, Pren y Durand (2009) señalan el efecto que tiene esta lucha antiterrorista sobre la población migrante:

Es en el contexto de la guerra antiterrorista en el que se definen nuevas políticas represivas dirigidas en contra de los inmigrantes. (...) Esta ley (la ley patriota) estaba dirigida contra los terroristas, pero en la práctica se declaró una guerra contra los extranjeros inmigrantes, que se materializó con el incremento del control fronterizo y la persecución de trabajadores ilegales al interior del país, que no tenían derecho a juicio ni apelación si existían razones para creer que podrían cometer o apoyar actos de terrorismo (p.108).

Dentro del contexto de seguridización, se debe considerar que los cambios aludidos, incluyen la percepción de amenazas, tal como ha sucedido en torno a las migraciones a raíz de los hechos mencionados.

La inmigración mexicana es enmarcada en una retórica de carácter marcial, militar. La frontera mexicana se considera como un "campo de batalla", que supuestamente está "bajo el ataque" de "extranjeros invasores". Se trata de una "bomba de tiempo" que puede "explotar" en cualquier momento y que puede destruir la sociedad "americana" (Massey et ál., 2009, p.110).

Las personas migrantes se han identificado como una amenaza y se les relaciona incluso con el crimen organizado. Por esta razón, se ha procedido a analizar los aspectos que se pueden resolver con las estrategias tradicionales de seguridad: se militarizan las fronteras $y$ se enfocan temas como la trata de personas y el tráfico de migrantes. Estas temáticas específicas resultan importantes desde un enfoque de seguridad, ya que pueden ser combatidas como otros delitos con fuerzas del orden y la aplicación de castigos a sus perpetradores; simultáneamente, se pueden justificar acciones como aumentos en el control fronterizo que a su vez tienden a desincentivar e incluso, disminuir la migración irregular.

\section{LA CRM}

En este contexto de seguridad, seguridización y en el marco de un complejo de seguridad existe y se desenvuelve la CRM, la cual se crea en 1996 como resultado de la cumbre presidencial Tuxtla II. Es un foro de discusión que incluye los siguientes países: Canadá, Estados Unidos, México, Guatemala, Honduras, El Salvador, Nicaragua, Costa Rica, Panamá y República Dominicana. Corresponde al Proceso regional consultivo sobre migración de la OIM, en Norte y Centroamérica. Sus objetivos incluyen el intercambio de información, mejores prácticas y experiencias en el tema migratorio, promover la cooperación regional sobre migración, además sus principios están relacionados con el diálogo, la coordinación, la cooperación regional y los DD.Hн.

Este proceso de seguridización se ha expandido a los procesos regionales consultivos $y$ la сRм no ha sido la excepción. En este caso, la seguridización afectó la intencionalidad original del foro dando paso a que se privilegie un enfoque de seguridad que enfatiza temas relativos a la trata de personas $y$ al tráfico de migrantes. Esto se puede percibir desde documentos como el plan de acción del Proceso Puebla, en el cual "temas tales como migración y desarrollo $y$ derechos de los migrantes que formaban parte de la declaración de 1996 están ausentes en este plan de acción” (Kron, 2011, p.66).

El papel preponderante de eE.uu. en la región, así como su capacidad financiera dentro de la сRм, ha favorecido que sus intereses y métodos prevalezcan en la organización. Si bien, la СRм como regionalismo no calza perfectamente en las regiones tradicionalmente definidas para el continente americano (Norteamérica, 
Centroamérica, El Caribe, Suramérica), es importante entender que los regionalismos no responden únicamente a factores geográficos, también manifiestan elementos culturales, es decir, son construidos socialmente.

El complejo de seguridad que conforman América Central y América del Norte es el espacio en el que se desarrolla la crm, la cual se puede clasificar como un regionalismo o régimen en materia de migración. Por la interdependencia entre los países y la interrelación entre las temáticas, se ha promovido la seguridización en la CRM, la cual no se logra desligar del complejo de seguridad como su contexto.

\subsection{LA SEGURIDIZACIÓN EN LA CRM}

Para profundizar esta temática, en el caso concreto de la crm, se muestra el análisis realizado, contrastando las declaraciones oficiales de la i y la xix Conferencia Regional sobre Migración.

Como punto de partida, es importante considerar que los tres documentos tienen como destinatarios los mismos países miembros y sus gobiernos, ya que en estos documentos se entablan compromisos - a pesar de no ser vinculantes-, se establecen acciones por realizar y se orienta el quehacer de los países en materia de migraciones.

\subsection{CONFERENCIA REGIONAL SOBRE MIGRACIÓN}

La primera cRm tuvo lugar en México en 1996 y reunió a representantes de diez países. Esta primera conferencia tuvo como resultado el comunicado conjunto de la I CRM, el cual plasma el reconocimiento de las migraciones como un tema relevante en la agenda internacional.

\subsubsection{COMUNICADO CONJUNTO DE LA I CONFERENCIA REGIONAL SOBRE MIGRACIÓN}

El primer documento analizado es el Comunicado conjunto de la I cRm de marzo, 1996. Al estudiar el escrito es significativo destacar su papel como documento fundacional de la cRm. Por lo tanto, posee importancia como el texto rector $y$ orientador de la conferencia. En el documento se recalca el uso de palabras como cooperación y cooperar, empleadas doce veces; seguida por las frases "derechos humanos" y "tráfico de migrantes", las cuales se emplean cinco veces cada una. Ello destaca las prioridades del documento.

Al examinar los resultados del análisis de contenido para el primer documento (cuadro 1), se observa que el énfasis recae en un enfoque de рD.нн. Esta categoría cuenta con 15 unidades con 34 repeticiones a lo largo del escrito. Simultáneamente, la categoría enfoque de seguridad cuenta con nueve unidades reiteradas 14 veces. Por lo tanto, se puede inferir que el mensaje del documento va orientado al establecimiento de un foro con un fuerte elemento de cooperación y un enfoque predominantemente de DD.HH.

\section{CUADRO 1 \\ RESUMEN ANÁLISIS DEL COMUNICADO \\ CONJUNTO DE LA I CONFERENCIA REGIONAL SOBRE MIGRACIONES, 1996}

\begin{tabular}{lc}
\hline Unidades & 24 \\
Palabras & 48 \\
Unidades DD.HH. & 15 \\
Unidades Seguridad & 9 \\
Total palabras DD.HH. & 34 \\
Total palabras Seguridad & 14 \\
\hline
\end{tabular}

Fuente: Elaboración propia.

La dinámica migratoria por su carácter internacional y la interdependencia entre las naciones para su manejo, evidencia la importancia del trabajo conjunto y la cooperación. Para abarcar grupalmente esta dinámica surge la necesidad de aprobar medidas conjuntas, la creación de un documento y el establecimiento de la conferencia. Además, se destaca la importancia de la región y la correlación de los países en un complejo de seguridad.

Con respecto a la intensidad, sobresale el enfoque de los DD.нH. con 34 palabras clasificadas en 15 unidades codificadas, observándose claramente tres niveles. La mayor intensidad recae sobre la palabra cooperación que se repite doce veces a lo largo del documento. La 
intencionalidad de la palabra aboga por una cooperación regional, ya que de las doce veces que se repite, cinco están acompañadas por la palabra regional. La intencionalidad en el documento y el enfoque cooperativo se recalcan al observarse que desde su preámbulo se habla de ambos: "reconocieron la necesidad de promover la cooperación regional dirigida a atenuar aquellos factores estructurales que motivan la migración en la región, sin perjuicio de los programas de cooperación bilateral" (сRM, 1996, p.1). Como documento fundacional de un foro regional es consecuente con que la cooperación regional sea priorizada.

Seguidamente, hay unidades con una intensidad moderada como lo son DD.Hн. $y$ tráfico de migrantes, con cinco repeticiones cada una. La primera se menciona nuevamente desde el preámbulo, se reafirma la soberanía de los Estados, aunque se reconocen los DD.Hн. de las personas migrantes. Posteriormente, se menciona en tres de los 21 acuerdos, entre ellos destaca "condenar las violaciones de los derechos humanos de los migrantes $y$ otros, independientemente de su condición migratoria, y luchar por la eliminación de dichas violaciones" (сRм, 1996, p.2). Esto evidencia los propósitos de la CRM y del documento.

Por su parte, tráfico de migrantes es una palabra clasificada en la categoría seguridad, pero está ausente del preámbulo, lo que puede interpretarse como una posición secundaria. Sin embargo, no se le puede obviar, ya que es parte de cuatro de los 21 acuerdos, que incluyen "coordinar esfuerzos para combatir a las organizaciones criminales dedicadas al tráfico de migrantes" (скм, 1996, p.3).

Por último, existe un nivel de palabras que son utilizadas con baja intensidad, pues son términos que se repiten tres o menos veces. En este caso, destacan en el enfoque de DD.Hн.: consulta (3 veces), enfoque integral (2 veces) y comprensión del fenómeno migratorio (1 vez). Para el enfoque de seguridad sobresalen organizaciones delictivas (2 veces ), así como erradicar actos ilegales (1 vez) y controlar los flujos de migrantes indocumentados extrarregionales (1 vez).

\subsection{CONFERENCIA REGIONAL SOBRE MIGRACIÓN}

La XIX CRM realizada en 2014, genera dos declaraciones que ilustran su quehacer actual. La primera proclama "por una región libre de trata de personas" y responde a las declaraciones que realiza anualmente el foro. Además, se realizó la "declaración extraordinaria de Managua", la cual responde a la coyuntura de la crisis de la niñez migrante.

Esta conferencia es relevante ya que se realiza después de varios cambios en el panorama internacional. La I cRM se da poco después de restaurada la paz en Centroamérica, lo que implicaba una disminución en las migraciones generadas por el conflicto. Sin embargo, en la actualidad estas han repuntado nuevamente debido a la inseguridad en el triángulo norte centroamericano, a las situaciones socioeconómicas y a la búsqueda de la reunificación familiar.

La globalización ha traído consigo nuevos fenómenos y retos a la administración fronteriza, tales como: el trasiego de mercancías, drogas, armas y las amenazas terroristas, que son tratados desde enfoques de seguridad y que han repercutido en el abordaje de la dinámica migratoria.

\subsubsection{LA DECLARACIÓN "POR UNA REGIÓN LIBRE DE TRATA DE PERSONAS"}

Esta declaración se desprende de la xix CRM, realizada en 2014, dentro de un panorama muy diferente. El cambio en el abordaje es evidente, la trata de personas es un problema que se plantea principalmente desde un enfoque de seguridad, se persigue y se castiga a los perpetradores, se toman medidas represivas. Sin embargo, el documento no excluye totalmente los рD.нн., en tanto también menciona la protección a las víctimas. El preámbulo del documento señala que en la conferencia se deliberó acerca de "los avances en la materia en sus respectivos países, principalmente el establecimiento de un marco jurídico que proteja a las víctimas y que castigue severamente a los tratantes de personas". Desde la redacción se puede ver una intencionalidad en el uso de adjetivos, se enfatiza como serán castigados 
los tratantes, severamente, sin embargo, no se hace lo mismo para describir cómo será la protección de las víctimas. Esto no es casualidad hay una clara intencionalidad y refuerza la priorización del enfoque de seguridad que acompaña al tema de trata de personas.

A nivel general, de 15 unidades de análisis; 7 corresponden a un enfoque de DD.Hн. $y$ 8 a un enfoque de Seguridad (cuadro 2). De 25 palabras, los enfoques de DD.Hн. $y$ Seguridad lograron 11 y 15 términos asignados respectivamente.

CUADRO 2

RESUMEN ANÁLISIS DE LA DECLARACIÓN "POR UNA REGIÓN LIBRE DE TRATA DE PERSONAS"

\begin{tabular}{lc}
\hline Unidades & 15 \\
Palabras & 26 \\
Unidades DD.HH. & 7 \\
Unidades Seguridad & 8 \\
Total palabras DD.HH. & 11 \\
Total palabras Seguridad & 15 \\
\hline
\end{tabular}

Fuente: Elaboración propia.

Esta situación contrasta con los resultados del documento analizado previamente, la temática general tiene una inclinación por abordajes de Seguridad, específicamente, al combate contra la trata de personas. Se promueve un mensaje de combate contra el crimen al enfatizar palabras como trata de personas (tratante), repetida seis veces en la declaración. Además, se acompaña de frases como lucha contra este flagelo, las cuales enmarcan la lucha como medio para enfrentar la trata de personas.

La palabra más usada correspondiente al enfoque de DD.Hн. es protección, la cual se debe entender como una vertiente del tema de la trata. Por lo tanto, los esfuerzos en vez de centrarse en la cooperación y en los DD.HH. (palabra que no se menciona en este documento), se enfocarán en el combate a la trata de personas $y$ en la seguridad.
La declaración "Por una región libre de trata de personas" es un documento orientador a nivel regional sobre los temas que deben ser considerados prioritarios y los esfuerzos que deben realizarse. Por su parte, el motivo por el cual se genera esta declaración es marcar la dirección y definir las pautas que deben seguir la organización y los Estados miembros. Esto se manifiesta en aspectos relacionados con la toma de decisiones en cuanto a la actuación que se debe dar, tal como ejemplifica el punto cinco: "aprobar el Manual de actuación en materia de trata de personas para las secretarías y ministerios de relaciones exteriores de Centroamérica y México" (скм, 2014b, p.2).

Para concluir el análisis del documento, es importante señalar que existe un cambio en la intensidad. Anteriormente, esta residía en el enfoque de DD.Hн., pero ahora se orienta a uno de seguridad, lo cual se evidencia desde el título de la conferencia hasta el vocabulario que emplea y el contenido de las decisiones aprobadas. Si bien, se menciona la protección de víctimas, esto no se refleja en las decisiones aprobadas por el foro. Este tiene 14 decisiones de las cuales 6 corresponden a formalidades, como agradecer a la sede del evento y asistentes, así como nombrar una nueva presidencia pro tempore y la aprobación de presupuestos. Dos de ellas se refieren a la crisis de la niñez migrante (ya que la declaración se realiza en medio de esta coyuntura) y una decisión se refiere a la elaboración de políticas migratorias.

Una resolución se refiere a la aprobación del manual antes mencionado sobre la actuación en materia de trata. Tres hablan sobre la realización de talleres o seminarios para la protección en caso de desastres naturales, sobre la prevención de la trata y los tramitadores migratorios inescrupulosos. Además, se felicita a República Dominicana por avances en materia de regulación de extranjeros en situación irregular. Finalmente, de 14 decisiones solamente una hace referencia a la protección de las víctimas de trata, las demás presentan otros temas o dan otros enfoques.

El vocabulario se demuestra con el uso de 15 palabras relativas al enfoque de seguridad divididas en 8 unidades de análisis. La palabra con mayor intensidad y la única con 
una intensidad alta responde a "trata de personas" repetida seis veces. El contexto donde esta se utiliza posee mayor relación con la persecución de los perpetradores y menos con la protección de las víctimas.

No hay términos que presenten una intensidad moderada. Las palabras usadas con una intensidad baja se incluyen en la categoría DD.HH. (palabras como protección). Esta es usada tres veces en relación directa con las víctimas de la trata de personas. Para el enfoque de seguridad, siempre con una intensidad baja se incluyen: retorno ( 2 veces) y "castigue severamente" (1 vez).

Asimismo, cuando se examinan los documentos de referencia que acompañan la información sobre la XIX conferencia en la página web de la cRm se destaca el documento "Trata de personas con fines de explotación laboral en Centro América", el cual marca una tendencia de seguridad con solo mirar el índice y el abordaje mayoritario, el cual se enmarca en la persecución y el castigo del crimen, dejando de lado la protección de las víctimas.

\subsubsection{DECLARACIÓN EXTRAORDINARIA DE MANAGUA}

$\mathrm{Al}$ igual que la anterior Declaración, esta se desprende de la xix crm realizada en 2014 en Managua, Nicaragua. Este documento tiene particular relevancia, debido a que responde a la crisis humanitaria de los niños, niñas y adolescentes no acompañados o separados en EE.uU. A simple vista se podría pensar que por ser la respuesta a una crisis humanitaria, la declaración extraordinaria poseería un enfoque de DD.HH.; sin embargo, su análisis no evidencia esto.

El análisis de contenido de la Declaración extraordinaria de Managua muestra 16 unidades de análisis: 7 se clasifican como relativas a un enfoque de DD.Hн. y 10 al de Seguridad (cuadro 3). Esta tendencia se mantiene al ver las repeticiones que tiene cada enfoque, el de DD.HH. tiene 14 vocablos asociados con ellos, mientras el de Seguridad tiene 18. Aunque el término más utilizado en el documento es protección (7 veces) tiende a estar acompañada por palabras como efectiva $y$ de los niños $y$ niñas. Pero esto se debe claramente a que la temática del documento así lo requiere, pero no garantiza que esto plasme un enfoque de DD.Hн.
Un aspecto por enfatizar es el regreso de la palabra cooperación (4 veces), la cual era vital en el primer documento y desaparece en la declaración anteriormente analizada. Sin embargo, por el contexto en el que se desenvuelve, se clasificaron dos de sus repeticiones como relativas a Seguridad y otras dos en torno a DD.нн.

En la clasificación de Seguridad, la primera hace referencia a la cooperación para implementar programas de reinserción y reintegración en las comunidades de origen, lo cual puede implicar deportaciones. Tal como lo señalan organizaciones como Acnur, esto es un aspecto riesgoso, ya que una parte importante de la infancia que migra lo hace escapando del crimen organizado y de situaciones que atentan contra el bien superior del niño. La segunda instancia en la que se clasificó como un elemento de seguridad es cuando sugiere cooperar en el combate contra el crimen organizado. Se calificó como una palabra relativa a los DD.Hн., cuando hizo referencia a cooperar para "hacer frente a las causas estructurales de este movimiento irregular de menores de edad..." (скм, 2014a, 1) y para la protección de personas migrantes.

El matiz de seguridad que rodea a la declaración extraordinaria se puede corroborar cuando se observa que palabras asociadas al tráfico de migrantes también se repiten cuatro veces, mientras las relacionadas al crimen organizado y a trata de personas aparecen tres veces cada una. Si bien, la palabra más utilizada se relaciona con los DD.Hн., se perciben más vocablos repetidos y una mayor cantidad de unidades asociadas con la seguridad.

CUADRO 3

\section{RESUMEN ANÁLISIS DE LA DECLARACIÓN EXTRAORDINARIA DE MANAGUA}

\begin{tabular}{lc}
\hline Unidades & 17 \\
Palabras & 32 \\
Unidades DD.HH. & 7 \\
Unidades Seguridad & 10 \\
Total palabras DD.HH. & 14 \\
Total palabras Seguridad & 18 \\
\hline
\end{tabular}

Fuente: Elaboración propia. 
Con base en lo planteado en el párrafo anterior, se puede concluir que la seguridad se encuentra presente en todo el documento. Incluso, cuando se trata un tema relacionado con una crisis humanitaria se aprovecha para enfatizar claramente tres aspectos de interés para el complejo de seguridad: el crimen organizado, el tráfico de migrantes y la trata de personas.

La motivación del documento es aclarar el campo en torno a una situación concreta. Como su mismo nombre lo indica, es una declaración extraordinaria; por lo tanto pretende responder a una coyuntura específica, en la cual se encuentran envueltos los Estados miembros de la crm.

Al estudiar las palabras más usadas, se muestra protección con una alta intensidad, pues posee siete repeticiones. Cooperación y tráfico de personas o traficante tienen una intensidad moderada con cuatro cada una y con una intensidad baja destacan los términos relacionados con el crimen organizado (grupos delictivos organizados, delincuencia organizada $y$ redes criminales) y trata de personas con tres repeticiones cada una. Además, las únicas palabras en DD.Hн. que se repiten son protección y cooperación. Se puede afirmar que el enfoque es de seguridad incluso frente a una crisis humanitaria, ya que las declaraciones presentan más repeticiones y más unidades en este caso.

A nivel general, se percibe un cambio en los documentos tanto en el vocabulario como en el enfoque, pues muestran un proceso de seguridización. Esto es evidente, debido a que solo el primer documento correspondía a DD.HH.

CUADRO 4

RESUMEN DE HALLAZGOS DEL ANÁLISIS DE CONTENIDO POR DOCUMENTOS

\begin{tabular}{lccc}
\hline & \multicolumn{3}{c}{ DECLARACIONES } \\
\cline { 2 - 4 } ELEMENTOS OBSERVADOS & I CRM & \multicolumn{2}{c}{ XIX CRM } \\
\cline { 2 - 4 } & COMUNICADO CONJUNTO & DECLARACIÓN & $\begin{array}{c}\text { DECLARACIÓN } \\
\text { EXTRAORDINARIA }\end{array}$ \\
\cline { 2 - 4 } Palabra más utilizada & Cooperación & Trata de Personas & Protección \\
\hline Unidades & 24 & 15 & 17 \\
Palabras & 48 & 26 & 32 \\
Unidades DD.HH. & 15 & 7 & 7 \\
Unidades Seguridad & 9 & 8 & 10 \\
Total palabras DD.HH. & 34 & 10 & 14 \\
Total palabras seguridad & 14 & 15 & Seguridad \\
Enfoque & Derechos humanos & Seguridad & \\
\hline
\end{tabular}

Fuente: Elaboración propia con base en los documentos analizados.

\section{CONCLUSIONES}

La importancia del espacio regional queda claramente evidenciado, tanto en una respuesta a problemáticas comunes como a un espacio natural de relación en complejos de seguridad, al depender la seguridad nacional no solo de las acciones o de la situación en su país, sino de los países vecinos.
En esta región en específico, la dinámica migratoria y la seguridad tienen un fuerte ligamen, más allá de temas asociados a la trata de personas y al tráfico de migrantes, lo cual ha dado un proceso de seguridización, que se refuerza a partir de los atentados del 11 de setiembre de 2001. Como consecuencia de este proceso, se militarizan las fronteras, se 
criminaliza al migrante, se detiene a personas que no han cometido ningún crimen por una violación administrativa, se rechazan solicitudes legítimas de refugio y se priva en muchos casos del disfrute de los DD.Hн. que poseen estas personas.

Es importante reconocer que desde sus inicios, la CRM presentaba un enfoque mayoritariamente relacionado con derechos humanos, sin embargo el enfoque de seguridad también estaba presente pero en menor medida. Este se relacionaba directamente con el tráfico de migrantes y la trata de personas; que fueron identificados claramente con la aparición de unidades relativas al enfoque de seguridad en el primer documento, así como, la conformación de las reuniones de viceministros de seguridad del interior, de gobernación y de relaciones exteriores. Sin embargo, esta no era la orientación dominante. El cambio está estrechamente ligado con los cambios en el contexto del complejo de seguridad.

El segundo documento muestra un componente mucho más fuerte en seguridad, el cual nace a partir de la temática de discusión de la conferencia "Por una región libre de trata" $y$ los fuertes matices de seguridad que envuelven la declaración extraordinaria, que se da por las dinámicas del momento; es decir, la CRM responde a los eventos acaecidos tanto a nivel general como específico.

La intensificación del enfoque de seguridad en la сRM puede responder al incremento de los esfuerzos estadounidenses por controlar sus fronteras; así como, a los aumentos en el accionar del crimen organizado en la región y a la necesidad de controlar el aumento significativo en la cantidad de individuos que son forzados a desplazarse desde el triángulo norte centroamericano. En lo específico, se observa como un evento específico concerniente a los países miembros del complejo: la crisis de la niñez migrante, dispara una reacción de parte de la CRM. Este evento está asociado al desplazamiento forzado $y$ afecta a una población en condición de vulnerabilidad sin embargo no logra desligarse del enfoque de seguridad que ha ganado terreno en la región y en la conferencia regional sobre migración.

\section{REFERENCIAS}

Abarca, A. (coord.) (2013). Técnicas Cualitativas de Investigación. San José, Costa Rica: Editorial UCR.

Benitez, R. y Sotomayor, A. (2008). El dilema mesoamericano: entre la inseguridad externa y la vulnerabilidad interna. En Lagos, R. (ed.) América Latina ¿Integración o Fragmentación? (pp.387417). Argentina: Fundación Grupo Mayan $\&$ EDHASA

Börze, T.; Goltermann, L.; Lohaus, M. \& Striebinger, K. (coord.) (2012). Roads to Regionalism: génesis, design, and effects of regional organizations. England: Ashgate Publishing Limited.

Buzan, B. (1991). People, States, and Fear: An Agenda for International Security Studies in the Post-Cold War Era: An alternative approach: Security complexes. Colorado, Ee.uU: Lynne Rienner.

Buzan, B.; Wæver, O. y de Wilde, J. (1998). Security: A new framework for analysis. Colorado, Ee.uv: Lynne Rienner.

Centro de Noticias onu. (2016). orm se convierte en parte del sistema de la onu. Recuperado de http://www. un.org/spanish/News/story.asp NewsID $=35829 \& K w 1=0 I M \& K w 2=\& K w 3$ $=\# . W J 3 f b v 195 \mathrm{~Pb}$

Centro Internacional para los Derechos Humanos de los Migrantes [сіDenum] y Alto Comisionado de las Naciones Unidas para Refugiados [acnuR]. (2012). Diagnóstico "Desplazamiento Forzado y Necesidades de Protección, generados por nuevas formas de Violencia $y$ Criminalidad en Centroamérica". Recuperado de http://www.acnur.org/t3/ fileadmin/Documentos/BDL/ 2012/8932. pdf?view $=1$.

Conferencia Regional sobre Migración-CRM (1996). Comunicado Conjunto de la I Conferencia Regional sobre Migración. Puebla, México. Recuperado de http://www.crmsv.org/ Eventos/CRM_GRCM/I_CRM.doc.

Conferencia Regional sobre Migración-CRM (2014a). Declaración Extraordinaria. 
Managua, Nicaragua. Recuperado de http://www.crmsv.org/Eventos/ CRM_GRCM/XIX_CRM_Declaracion_ extraordinaria.docx

Conferencia Regional sobre MigraciónCRM (2014b). Declaración y Decisiones de los(as) Viceministros(as) en la XIX Conferencia Regional sobre Migración. Managua, Nicaragua. Recuperado de http://www.crmsv.org/Eventos/CRM_ GRCM/XIX_CRM.doc.

Farrelll, M.; Hettne, B.; y Van Langenhove, L. (coord.) (2005). Global Politics of Regionalism: Theory and Practice. London: Ann Arbor, MI; Pluto Press.

González, Á. (2012). Estudios críticos de seguridad, migraciones internacionales $y$ ayuda al desarrollo. Simposio realizado en el XI Congreso Política en tiempos de incertidumbre. Sevilla, España. Recuperado de http://www.aecpa.es/ uploads/files/modules/congress/11/ papers/1010.pdf

Instituto Interamericano de Derecho Humanos [IIDH]. (s.f). La seguridad humana en América Latina. Recuperado de https://www.iidh.ed.cr/multic/ default_12.aspx?contenidoid $=8 \mathrm{c} 1 \mathrm{a} 302 \mathrm{f}$ f00e-4f67-b3e6-8a3979cf15cd\&Portal= IIDHSeguridad.

Kron, S. (2011). Gestión migratoria en Norte y Centroamérica: manifestaciones Y contestaciones. Anuario de Estudios Centroamericanos, 37, 53-85.

Massey, D.; Pren, K.; y Durand, J. (julio-septiembre, 2009). Nuevos escenarios de la migración México-Estados Unidos:
Las consecuencias de la guerra antiinmigrante. Papeles de Población 15,(61), 101-128.

Organización Internacional para las Migraciones [огм] (2013). Procesos Consultivos Regionales sobre Migración. Recuperado de https://www.iom.int/files/ live/sites/iom/files/What-We-Do/docs/ RCP-Infosheet-2013-SP.pdf

Organización Internacional para las Migraciones [огм]. (2006). Glosarios sobre Migración. Ginebra, Suiza: оIм

Orozco, G. (diciembre-enero, 2005). El concepto de la seguridad en la teoría de las relaciones internacionales. Revista СIDов d'Afers Internacionals (72), 161-180.

Panting, C. (18 de mayo de 2016). Analistas ven amenaza en tanques de Nicaragua. La Prensa.hn. Recuperado de http:// www.laprensa.hn/honduras/961321-410/ analistas-ven-amenaza-en-tanques-denicaragua

Sisco, C. y Chacón, O. (enero-junio de 2014). Barry Buzan y la teoría de los complejos de seguridad, (25). Revista Venezolana de Ciencia Política, 125-146.

United States Embassy-Mexico. (2015). Iniciativa Mérida- Panorama general. Recuperado de http://spanish.mexico.usembassy. gov/es/temas-bilaterales/mexico-y-eu-deun-vistazo/iniciativa-merida.html

Fecha de ingreso: 27/09/2016 Fecha de aprobación: 15/02/2017 